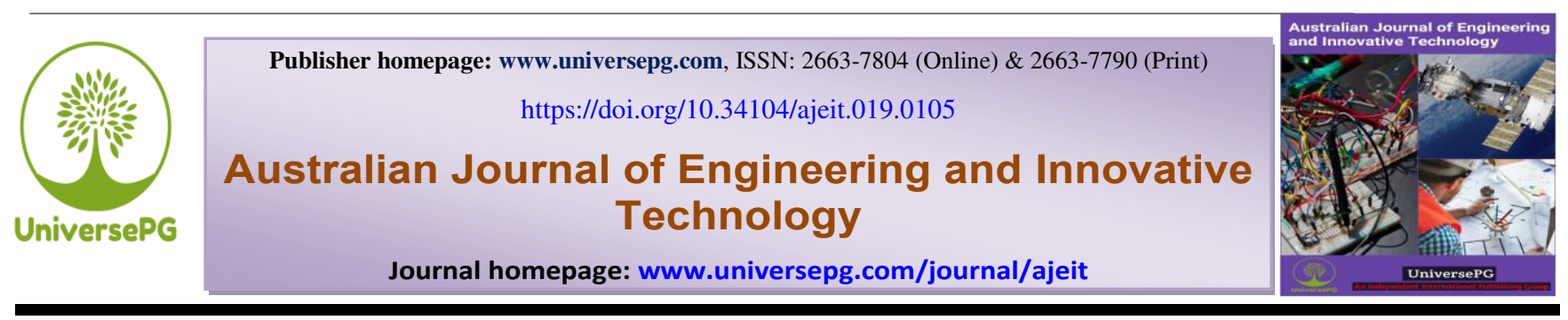

\title{
Dust Ion Acoustic Solitary Waves in Multi-Ion Dusty Plasma System
}

\author{
Kazi Asraful Islam ${ }^{1}$, F. Deeba ${ }^{2}$, and Md. Kamal-Al-Hassan ${ }^{3}$ \\ ${ }^{1}$ Dept. of Textile Engineering, Sonargaon University, Dhaka-1212, Bangladesh; and ${ }^{2 \& 3}$ Dept. of Physics, Dhaka University \\ of Engineering \& Technology, Gazipur-1707, Bangladesh.
}

*Correspondence: kazinooman@gmail.com

\begin{abstract}
A theoretical work has done to observe the existence of dust ion-acoustic (DIA) solitary waves (SWs) in a multi-ion dusty plasma system consisting of inertial positive and negative ions, Maxwell's electrons, and arbitrary charged stationary dust. In this short communication, our research declares that with these components the derivation of Korteweg-de Vries (K-dV) and mixed K-dV (mK-dV) is possible. Here reductive perturbation method has been employed in all these approaches. The first K-dV equation has been derived which gave both bright and dark solitons but for a very limited region. Then the $\mathrm{mK}-\mathrm{dV}$ equation has been derived that gave bright soliton for a large region, but no dark soliton has been observed.
\end{abstract}

Keywords: Dusty plasma, Ion acoustic wave, Multi-ion, DIA, Space plasma system, K-dV, and mK-dV.

\section{INTRODUCTION:}

Dusty plasma is normal electron-ion plasma with an added highly charged element of small micron or submicron sized extremely massive charged gritty (dust grains). Shukla and Silin, (1992) have theoretically shown the low-frequency dust-ion-acoustic waves in a dusty plasma system. Barkan et al. (1995) have experimentally verified the existence of dust-ionacoustic wave in dusty plasma. These waves differ from usual ion-acoustic waves (Lonngren, 1983) due to the conservation of equilibrium charge density $\mathrm{n}_{\mathrm{e} 0} \mathrm{e}+\mathrm{n}_{\mathrm{d} 0} \mathrm{Z}_{\mathrm{de}}-\mathrm{n}_{\mathrm{i} 0} \mathrm{e}=0$, and the strong inequality, $\mathrm{n}_{\mathrm{e} 0} \ll$ $\mathrm{n}_{\mathrm{i} 0}$, where $\mathrm{n}_{\mathrm{s} 0}$ is the particle number density of the species $\mathrm{s}$ with $\mathrm{s}=\mathrm{e}$ (i) d for electrons (ions) dust, $\mathrm{Z}_{\mathrm{d}}$ is the figure of electrons residing onto the dust grain side, and e is the magnitude of an electronic charge. DIA wave's linear properties are now prudent understood (Shukla and Mamun, 2002; Barkan et al., 1996; and Shukla and Rosenberg, 1999).
The nonlinear structures related with the DIA waves are particularly solitary waves (Bharuthram and Shukla, 1992; Nakamura and Sharma, 2001); shock waves (Nakamura et al., 1999; Luo, 2000; and Mamun and Shukla, 2002), etc. These waves have also had a great deal of interest to understand the localized electrostatic perturbations in galactic space (Geortz, 1989; Fortov, 2005), and laboratory dusty plasmas (Shukla and Mamun, 2002; Nakamura and Sharma, 2001, and Barkan et al., 1996).

Dusty plasmas create a fully modern interdisciplinary area with direct link to astrophysics, nanoscience, fluid mechanics, and material science as specified through experimental, theoretical, analytical, and arithmetical studies. All of these works (Shukla and Mamun, 2002; Bharuthram and Shukla, 1992; Nakamura and Sharma, 2001; Nakamura et al., 1999; Luo, 1995; Mamun, 2009) are limited to planar (1D) geometry and are subjected to some critical value. 
A few works have also been done on finite amplitude DIA solitons and shock structures (Luo, 1995), where $\mathrm{K}-\mathrm{dV}$ or Burgers equations are used, which are not valid because, the latter gives infinitely large amplitude structures which break down the validity of the reductive perturbation method) for a parametric regime corresponding to $\mathrm{A}=0$ or $\mathrm{A} \sim 0$ (where $\mathrm{A}$ is the coefficient of the nonlinear term of the K-dV or Burgers equation) (Luo, 1995).

Here, $\mathrm{A} \sim 0$ means $\mathrm{A}$ is not equal to 0 , but $\mathrm{A}$ is around 0 . In our present work, we have been able to show the bright and dark solitons for a large region of multi-ion dusty plasma system in an adiabatic state.

The manuscript is prepared as follows; the model equations are given in Sec. 2, the K-dV equation is derived in Sec. 3, the $\mathrm{mK}-\mathrm{dV}$ equation is derived in Sec. 4, then results and discussion are given in Sec. 5, and conclusion is given in Sec. 6 .

\section{Model Equations}

The dynamics of the one-dimensional multi-ion DIA waves are governed by:

$$
\begin{aligned}
& \partial \mathrm{n}_{\mathrm{s}} / \partial \mathrm{t}+\partial \mathrm{n}_{\mathrm{s}} \mathrm{u}_{\mathrm{s}} / \partial \mathrm{x}=0 \\
& \partial \mathrm{u}_{\mathrm{i}} / \partial \mathrm{t}+\mathrm{u}_{\mathrm{i}} \partial \mathrm{u}_{\mathrm{i}} / \partial \mathrm{x}=-\partial \psi / \partial \mathrm{x}-\left(\delta_{\mathrm{i}} / \mathrm{n}_{\mathrm{i}}\right)\left(\partial \mathrm{p}_{\mathrm{i}} / \partial \mathrm{x}\right) \\
& \partial \mathrm{u}_{\mathrm{n}} / \partial \mathrm{t}+\mathrm{u}_{\mathrm{n}} \partial \mathrm{u}_{\mathrm{n}} / \partial \mathrm{x}=1 / \mu\left(\partial \psi / \partial \mathrm{x}-\delta_{\mathrm{n}} / \mathrm{n}_{\mathrm{n}} \partial \mathrm{p}_{\mathrm{n}} / \partial \mathrm{x}\right) \\
& \mathrm{e} \partial \psi / \partial \mathrm{x}-1 / \mathrm{n}_{\mathrm{e}} \partial \mathrm{p}_{\mathrm{e}} / \partial \mathrm{x}=0 \\
& \partial \mathrm{p}_{\mathrm{s}} / \partial \mathrm{t}+\mathrm{u}_{\mathrm{s}} \partial \mathrm{p}_{\mathrm{s}} / \partial \mathrm{x}+\gamma \mathrm{p}_{\mathrm{s}} \partial \mathrm{u}_{\mathrm{s}} / \partial \mathrm{x}=0 \\
& \partial^{2} \psi / \partial \mathrm{x}^{2}=\left[1-\mu_{\mathrm{n}}+\mu_{\mathrm{d}}\right] \exp ^{\psi}+\mu_{\mathrm{n}} \mathrm{n}_{\mathrm{n}}-\mu_{\mathrm{d}}-\mathrm{n}_{\mathrm{i}}
\end{aligned}
$$

where $n_{s}$ is the number density with $s=n(i) e(d)$ of negative ion (positive ion) electron (stationary dust), $u_{s}$ is the fluid speed of $s, m_{j}$ is the positive (when $j=i$ ) or negative (when $j=n$ ) ion mass, $Z_{d}$ is the number of electron occupy on the dust grain side, $\mathrm{e}=$ magnitude of the electron-charge (q), $\phi$ is the electrostatic wave potential; $\mathrm{n}_{\mathrm{s} 0},\left(\mathrm{n}_{\mathrm{j} 0}\right)$, and $\mathrm{n}_{\mathrm{d} 0}$ are the equilibrium value of $n_{s},\left(n_{j}\right)$, and $n_{d}$ respectively i.e. $n_{s},\left(n_{j}\right)$, and $n_{d}$ are the number density normalized by $\mathrm{n}_{\mathrm{s} 0},\left(\mathrm{n}_{\mathrm{j} 0}\right)$, and $\mathrm{n}_{\mathrm{d} 0}$ respectively, $p_{i}$ is the pressure of species $i, \gamma$ is an adiabatic index, $\mathrm{x}$ is the space variable, and $\mathrm{t}$ is the time variable.

\section{K-dV Equation}

For the DIA K-dV equation we introduce the stretched coordinates:

$\zeta=\epsilon^{1 / 2}\left(\mathrm{x}-\mathrm{V}_{\mathrm{p}} \mathrm{t}\right)$, and $\tau=\epsilon^{3 / 2} \mathrm{t}$,

Where, $V_{p}$ is the wave phase speed $(\omega / \mathrm{k})$, and $\epsilon$ is a smallness parameter $(0<\epsilon<1)$.

To get the dispersion relation, we expand $n_{s}, u_{s}, p_{s}$, and $\phi$ with $\mathrm{s}$ be the charged species like positive and negative ion, electron in power series of $\epsilon$, to their equilibrium and perturbed parts,

$$
\begin{aligned}
& \mathrm{n}_{\mathrm{s}}=1+\epsilon \mathrm{n}_{\mathrm{s}}^{(1)}+\epsilon^{2} \mathrm{n}_{\mathrm{s}}^{(2)}+\epsilon^{3} \mathrm{n}_{\mathrm{s}}^{(3)}+\cdots, \\
& \mathrm{u}_{\mathrm{s}}=0+\epsilon \mathrm{u}_{\mathrm{s}}^{(1)}+\epsilon^{2} \mathrm{u}_{\mathrm{s}}^{(2)}+\epsilon^{3} \mathrm{u}_{\mathrm{s}}^{(3)}+\cdots, \\
& \mathrm{p}_{\mathrm{s}}=0+\epsilon \mathrm{p}_{\mathrm{s}}^{(1)}+\epsilon^{2} \mathrm{p}_{\mathrm{s}}^{(2)}+\epsilon^{3} \mathrm{p}_{\mathrm{s}}^{(3)}+\cdots, \\
& \psi=0+\epsilon \psi^{(1)}+\epsilon^{2} \psi^{(2)}+\epsilon^{3} \psi^{(3)}+\cdot \cdot,
\end{aligned}
$$

Where $\mathrm{n}_{\mathrm{s}}^{(1)}, \mathrm{u}_{\mathrm{s}}^{(1)}, \mathrm{p}_{\mathrm{s}}^{(1)}$, and $\psi^{(1)}$ are the perturbed part of $n_{s}, u_{s}, p_{s}$, and $\psi$ respectively.

Combining above equations, we get -

$\mathrm{V}_{\mathrm{p}}=(-\mathrm{b} \pm \sqrt{ }(\mathrm{b} 2-4 \mathrm{ac}) / 2 \mathrm{a})^{(1 / 2)}$

Where,

$\alpha=\left(1-\mu_{\mathrm{n}}+\mu_{\mathrm{d}}\right), \mathrm{a}=\mu \alpha, \mathrm{b}=\mu_{\mathrm{n}}+\mu-\alpha \gamma \delta_{\mathrm{n}}-\alpha \mu \gamma \delta_{\mathrm{i}}$, and $\mathrm{c}=\alpha \gamma^{2} \delta_{\mathrm{n}} \delta_{\mathrm{i}}-\gamma \delta_{\mathrm{n}}-\gamma \delta_{\mathrm{i}} \mu_{\mathrm{n}}$.

Equation (12) represents linear dispersion relation.

The next higher order of $\epsilon$ can be simplified as an equation of the form:

$\partial \psi / \partial \tau+A \psi \partial \psi / \partial \zeta+\beta \partial^{3} \psi / \partial^{3} \zeta=0$

Where,

$\mathrm{A}=\mathrm{Y} / \mathrm{X}$,

$\beta=1 / X$,

$\mathrm{X}=\left(2 \mathrm{~V}_{\mathrm{p}} / \mathrm{d}_{2}^{2}\right)\left(2 \mathrm{~V}_{\mathrm{p}} \mu \mu_{\mathrm{n}} / \mathrm{d}_{1}\right)$, 
$\mathrm{Y}=-\mathrm{c}_{1} / \mathrm{d}_{2}{ }^{3}+\mu_{\mathrm{n}} \mathrm{c}_{2} / \mathrm{d}_{1}{ }^{3}+\mu_{\mathrm{n}} \mathrm{c}_{3} / \mathrm{d}_{1}{ }^{3}, \quad 1 / 2\left\{\mathrm{~A}\left(\psi^{(1)}\right)^{2}\right\}=0$

$\mathrm{c}_{1}=\mathrm{V}_{\mathrm{p}}^{4}+2 \mathrm{~V}_{\mathrm{p}}^{2} \gamma \delta_{\mathrm{i}}-3 \mathrm{~V}_{\mathrm{p}}^{2}+\gamma^{2} \delta_{\mathrm{i}}^{2}-2 \gamma \delta_{\mathrm{i}}+\gamma^{2} \delta_{\mathrm{i}}$

$\mathrm{c}_{2}=\mathrm{V}_{\mathrm{p}}^{4} \mu^{2}-2 \mu \mathrm{V}_{\mathrm{p}}^{2} \gamma \delta_{\mathrm{n}}+3 \mu \mathrm{V}_{\mathrm{p}}^{2}$,

$c_{3}=\gamma^{2} \delta_{n}^{2}+2 \gamma \delta_{n}-\gamma^{2} \delta_{n}$.

Equation (13) is known as $\mathrm{K}-\mathrm{dV}$ equation. We get stationary localized solution of (13) by introducing a transformation $\xi=\zeta-\mathrm{U}_{0 \tau}$;

$\psi=\psi_{\mathrm{m}} \operatorname{sech}^{2}\left[\left(\zeta-\mathrm{U}_{0 \tau}\right) / \delta\right]$,

Where the amplitude $\psi_{\mathrm{m}}$ and the width $\delta$ are given by $\psi_{\mathrm{m}}=3 \mathrm{U}_{0} / \mathrm{A}$, and $\delta=\sqrt{ } 4 \beta / \mathrm{U}_{0}$, respectively.
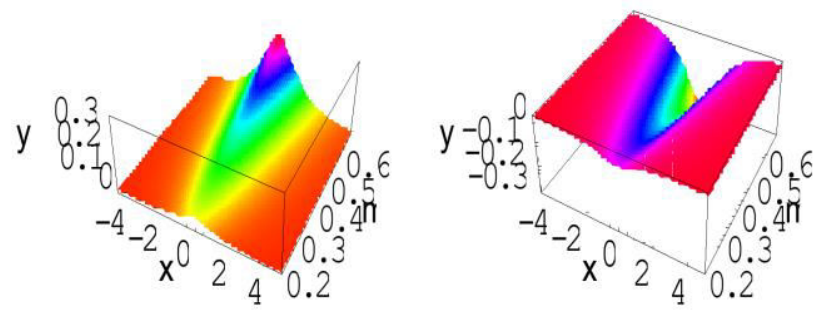

Fig 1: Bright and dark K-dV solitons.

Equation (14) is the solution of K-dV equation. This represents a solitary wave. We observed that the Fig 1 shows the existence of bright and dark K-dV solitons with mass number density $(\mu)$.

\section{mK-dV Equation}

For the third order calculation a new set of stretched coordinates is applied:

$\zeta=\epsilon\left(x-V_{p} t\right), \tau=\epsilon^{3} t$,

Using (15) we can find the same values of $\mathrm{n}_{\mathrm{i}}{ }^{(1)}, \mathrm{n}_{\mathrm{n}}{ }^{(1)}$, $\mathrm{n}_{\mathrm{e}}{ }^{(1)}, \mathrm{u}_{\mathrm{i}}{ }^{(1)}, \mathrm{u}_{\mathrm{e}}{ }^{(1)}, \mathrm{u}_{\mathrm{n}}{ }^{(1)}, \mathrm{p}_{\mathrm{i}}{ }^{(1)}, \mathrm{p}_{\mathrm{e}}{ }^{(1)}, \mathrm{p}_{\mathrm{n}}{ }^{(1)}$, and $\mathrm{V}_{\mathrm{p}}$ as like as that in $\mathrm{K}-\mathrm{dV}$.

To the next order approximation of $\epsilon$, we obtain a set of equations, which, after using the values $\mathrm{n}_{\mathrm{i}}{ }^{(1)}, \mathrm{n}_{\mathrm{n}}{ }^{(1)}$, $\mathrm{n}_{\mathrm{e}}{ }^{(1)}$, and $\mathrm{V}_{\mathrm{p}}$, can be simplified and applying the condition, $\psi \neq 0$ (so, it's coefficient is zero), we get,
For the next higher order of $\epsilon$, we obtain an equation:

$\partial \psi / \partial \tau+\alpha \beta \psi^{2} \partial \psi / \partial \zeta+\beta \partial^{3} \psi / \partial \zeta^{3}=0$,

Where,

$\alpha=\mathrm{F}\left(-\mathrm{a}_{1}{ }^{2}+15 / 2-21 \gamma \delta_{\mathrm{n}} / 2 \mathrm{a}_{1}-5 \gamma^{2} \delta_{\mathrm{n}} / 2 \mathrm{a}_{1}\right.$

$\left.-3 \gamma^{3} \delta^{2}{ }_{n} / a_{1}{ }^{2}\right)-F\left(3 \gamma^{2} \delta_{n}{ }^{2} / a_{1}{ }^{2}\right)+\mathrm{G}\left(\mathrm{a}_{2}{ }^{2}-15 / 2\right.$

$\left.-21 \gamma \delta_{\mathrm{i}} / 2 \mathrm{a}_{2}\right)-\mathrm{G}\left(5 \gamma^{2} \delta_{\mathrm{i}} / 2 \mathrm{a}_{2}-3 \gamma^{3} \delta_{\mathrm{i}}{ }^{2 / \mathrm{a}_{2}}{ }^{2}-3 \gamma^{2} \delta_{\mathrm{i}}{ }^{2} / \mathrm{a}_{2}{ }^{2}\right)$,

$\beta=\mathrm{V}_{\mathrm{p}} \mathrm{a}_{1}^{2} \mathrm{a}_{2}^{2} /\left(-2 \mu \mu_{\mathrm{n}} \mathrm{a}_{2}^{2} \mathrm{~V}_{\mathrm{p}}^{2}-2 \gamma \delta_{\mathrm{i}} \mathrm{a}_{1}^{2}\right)$,

Where,

$\mathrm{F}=\mu_{\mathrm{n}} / \mathrm{a}_{1}{ }^{3}, \mathrm{G}=1 / \mathrm{a}_{2}{ }^{3}, \mathrm{a}_{1}=\left(\gamma \delta_{\mathrm{n}}-\mu \mathrm{V}_{\mathrm{p}}{ }^{2}\right)$, and

$\mathrm{a}_{2}=\left(\mathrm{V}_{\mathrm{p}}^{2}-\gamma \delta_{\mathrm{i}}\right)$.

Equation (17) is known as mK-dV equation. The stationary localized solution of (17), obtained by introducing a transformation $\xi=\zeta-\mathrm{U}_{0} \tau$, is, therefore, directly given by

$\psi=\psi_{\mathrm{m}} \operatorname{sech}[\xi / \Delta]$,

Where the amplitude $\psi_{\mathrm{m}}$ and the width $\delta$ are given by $\psi_{\mathrm{m}}=\sqrt{ } 6 \mathrm{U}_{0} / \alpha \beta$, and $\delta=1 / \psi_{\mathrm{m}} \sqrt{ } \gamma$. where the amplitude $\psi_{\mathrm{m}}$ and the width $\Delta$ are given by $\psi_{\mathrm{m}}=\sqrt{ }_{6} \mathrm{U}_{0} / \alpha \beta, \Delta=$ $1 /\left(\sqrt{ } \gamma \psi_{\mathrm{m}}\right)$, and $\gamma=\alpha / 6$.

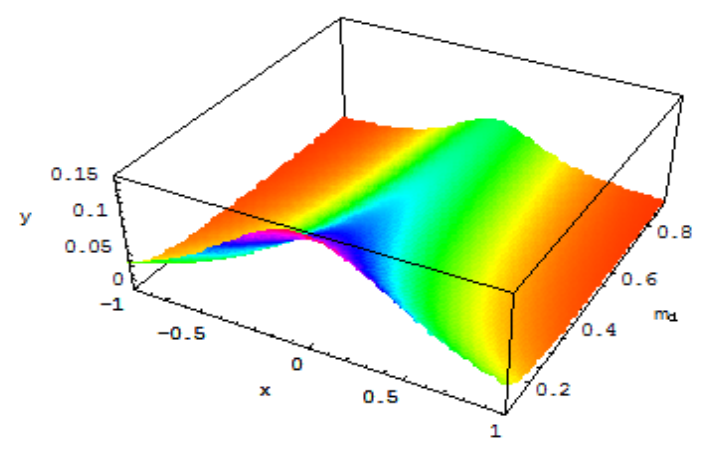

Fig 2: Bright mK-dV soliton.

Fig 2 gives the existence of $\mathrm{mK}-\mathrm{dV}$ solitons. We get only one type of solitons, bright solitons. 


\section{RESULTS AND DISCUSSION:}

Dust ion acoustic $\mathrm{K}-\mathrm{dV}$ and $\mathrm{mK}-\mathrm{dV}$ solitons have been investigated in a multi-ion dusty plasma system where we observed;

1. The positive and negative $\mathrm{K}-\mathrm{dV}$ solitons are observed.

2. The width and amplitude of the K$\mathrm{dV}$ solitons varies with polaritychanges.

3. Existence of positive $\mathrm{mK}-\mathrm{dV}$ solitons is observed.

\section{CONCLUSION:}

Present investigation are valid for tiny amplitude DIA K-dV, and mK-dV solitons. The first K-dV equation has been derived which gave both bright and dark solitons but for a very limited region. Though we have considered positive and negative ions, Maxwell's electrons, and arbitrarily charged stationary dust, our model is applicable for small amplitude waves only.

\section{ACKNOWLEDGEMENT:}

We are so much acknowledged to Prof. Dr. Md. Kamal-Al- Hassan and Asst. Prof. Dr. Farah Deeba for their guidance to this research.

\section{CONFLICTS OF INTEREST:}

The authors declare that they have no competing interests with respect to the research.

\section{REFERENCES:}

1. Barkan A., Angelo N. D, and Merlino R. L., (1996). "Experiments on ion-acoustic waves in dusty plasmas," Planet. Space Sci., 44, pp. 239-242. https://doi.org/10.1016/0032-0633(95)00109-3

2. Barkan A., Merlino R. L. and Angelo N. D, (1995). "Laboratory monitoring of the dustacoustic wave mode," Phys. Plasmas, 21, pp. 3563.

https://citeseerx.ist.psu.edu/viewdoc/download?d oi=10.1.1.1040.4162\&rep=rep1\&type $=$ pdf
3. Barkan A., Angelo N. D and Merlino R. L., (1996). "Experiments on ion-acoustic waves in dusty plasmas," Planet. Space Sci., 44, pp. 239.

https://doi.org/10.1016/0032-0633(95)00109-3

4. Bharuthram R. and Shukla P. K., (1992). Large amplitude ion-acoustic solitons in dusty plasma, Planet. Space Sci., 40, pp. 973. https://doi.org/10.1016/0032-0633(92)90137-D

5. Bliokh, P., Sinitsin, V. and Yaroshenko, V. (1995). Dusty and Own-Gravitational Plasmas in Space. Dordrecht, Netherlands: Kluwer. https://link.springer.com/content/pdf/bfm\%3A97 8-94-015-8557-6\%2F1.pdf

6. Fortov V. E., (2005). Basics of dusty plasma, Phys. Rep., 31(1), pp 46-56.

7. Geortz C. K., (1989). Dusty plasmas in the solar system, Rev. Geophys., 27, pp. 271. https://doi.org/10.1029/RG027i002p00271

8. Lonngren K. E., (1983). "Soliton experiments in plasmas," Plasma Phys., 25, pp. 943-982.

9. Luo Q. Z., (2000). Ion acoustic shock formation in converging magnetic field geometry, Phys. Plasmas, 7, pp. 3457. https://doi.org/10.1063/1.874074

10. Mamun A A and Shukla P. K., (2002). Cylindrical, and spherical dust ion-acoustic solitary waves, IEEE Trans. Plasma Sci., 30, pp. 720. https://doi.org/10.1063/1.1458030

11. Mamun A. A., (2009). "Solitary waves and double covers in a dusty electronegative plasma", Phys. Rev. E, 80, pp. 046406. https://doi.org/10.1103/PhysRevE.80.046406

12. Nakamura Y., Bailung H., and Shukla P. K., (1999). "Observation of ion-acoustic shocks in a dusty plasma," Phys. Rev. Lett., 83, pp. 1602-1605.

https://doi.org/10.1103/PhysRevLett.83.1602

13. Nakamura Y. and Sharma A., (2001). NMR study of the magnetic properties of the quasione-dimensional conductor (TMTTF), Phys. Plasmas, 8, pp. 3931.

14. Shukla P. K. and Rosenberg M., (1999). "Boundary effects on dust-ion-acoustic and 
dust-acoustic waves in collisional dusty plasmas," Phys. Plasmas, 6, pp. 1038. https://doi.org/10.1063/1.873345

15. Shukla P. K., and Silin V. P., (1992). "Dust ion acoustic wave," Phys. Scripta, 45, p. 508. https://doi.org/10.1088/0031-8949/45/5/015

16. Shukla P. K. and Mamun A. A., (2002). "Introduction to Dusty Plasman Physics,"
Institute of Physics Publishing Ltd. Bristol, ISBN 075030653X.

17. Verheest, F. (2002). Waves in Dusty Space Plasmas. Dordrecht, Netherlands: Kluwer. https://www.springer.com/gp/book/9781402003 $\underline{738}$

Citation: Islam KA, Deeba F, and Hassan MKA. (2019). Dust ion acoustic solitary waves in multi-ion dusty plasma system with adiabatic thermal change, Aust. J. Eng. Innov. Technol., 1(5), 1-5. https://doi.org/10.34104/ajeit.019.0105 C) $\underset{\mathrm{EY}}{\mathrm{C}}$ 